Seminário de Pesquisa em Ciência da Informação do PPGCI 2017

Escola de Comunicações e Artes - Universidade de São Paulo

\title{
INFORMAÇÃO E EDUCAÇÃO: UM ESTUDO DO RELATÓRIO \\ “THE INFORMATION SERVICE ENVIRONMENT: RELATIONSHIPS AND PRIORITIES”, DE PAUL ZURKOWSKI
}

\author{
INFORMATION AND EDUCATION: A STUDY OF THE REPORT \\ “THE INFORMATION SERVICE ENVIRONMENT: RELATIONSHIPS AND \\ PRIORITIES”, BY PAUL ZURKOWSKI
}

\section{Leandro dos Santos Nascimento \\ Edmir Perrotti}

\begin{abstract}
Resumo: O relatório "The information Service Environment Relationships and Priorities", de Paul G. Zurkowski (1974), tornou-se a base para um movimento de proporções globais, conhecido como Information Literacy. Mobilizando pesquisadores, profissionais, políticas e entidades públicas e privadas, tal movimento disseminou-se, também, no Brasil, sem ter, todavia, suas bases analisadas e compreendidas, suficientemente. Diante disso, nosso objetivo é levantar e refletir sobre as ideias fundamentais do documento e das óticas informacional e educacional que sustentam a proposta inicial da Information Literacy, sendo utilizado no estudo o método da análise do discurso. Preliminarmente, percebe-se um discurso enraizado nos postulados da Sociedade da Informação e com forte tendência economicista e instrumental. A pesquisa pauta-se pela perspectiva da Infoeducação, abordagem transdisciplinar que oferece elementos ao desenvolvimento de bases teóricas e metodológicas necessárias à superação da razão instrumental que orienta o relatório que deu origem à Information Literacy.
\end{abstract}

Palavras-chave: Análise do Discurso, Infoeducação, Information Literacy, Paul Zurkowski, Sociedade da Informação.

Abstract: The Paul G. Zurkowski's report "The Information Service Environment Relationships and Priorities" (1974) became the basis for a movement of global proportions known as Information Literacy. Mobilizing researchers, professionals, politicians, and public and private entities, this movement has spread, even in Brazil, without having its bases analyzed and sufficiently understood. Therefore, our objective is to analyze and understand the fundamental ideas of the document and the informational and educational perspectives that support the initial proposal of Information Literacy, being used in the study the method of discourse analysis. Preliminarily, is perceived a discourse rooted in the postulates of the Information Society and with a strong economicist and instrumental tendency. The research is guided by the perspective of the Infoeducation, a transdisciplinary approach that offers elements to the development of theoretical and methodological bases necessary to overcome the instrumental reason that guides the report that gave rise to Information Literacy.

Keywords: Discourse Analysis, Infoeducation, Information Literacy, Information Society, Paul Zurkowski.

\section{$1 \quad$ Introdução}

As relações entre os campos da Informação e da Educação são tratadas com frequência na sociedade atual, seja em função do constante desenvolvimento tecnológico, seja pela avalanche que caracteriza a cultura informacional na contemporaneidade e a ansiedade informacional dela decorrente. Nesse cenário, um dos movimentos de grande destaque é o da "Information Literacy" (IL), que no Brasil é traduzido na maioria das vezes como "competência", "alfabetização" ou "letramento informacional". 
Seminário de Pesquisa em Ciência da Informação do PPGCI 2017

Escola de Comunicações e Artes - Universidade de São Paulo

Este movimento tem suas origens em 1974, com o relatório "The Information Service Environment: Relationships and Priorities", de Paul Zurkowski, apresentado à Comissão Nacional de Biblioteconomia e Ciência da Informação americana. Como presidente da Associação das Indústrias da Informação, dos Estados Unidos, Zurkowski apresentou um panorama dos recursos oferecidos pela indústria da informação, bem como comparou os serviços oferecidos pelas bibliotecas e explicitou as mudanças que estavam ocorrendo entre ambos, que sofriam forte influência do desenvolvimento tecnológico. A partir da constatação desse cenário mutável, os cidadãos americanos não possuíam as habilidades para utilizar os recursos de informação disponíveis e que viessem a ser desenvolvidos. Assim, Zurkowski sugere à Comissão a criação de um programa que tornasse as pessoas information literates, a ser desenvolvido entre os anos de 1974 a 1984.

Inicialmente, a proposta de Zurkowski expandiu-se pelos Estados Unidos e, posteriormente, ganhou amplitude global, amparada, sobretudo pelo discurso da chamada Sociedade da Informação e o ideal da globalização. É fato inquestionável que o objetivo da Information Literacy desenvolveu-se, ganhou adeptos por todo o planeta, com diversos profissionais, instituições e políticas debruçados sobre a questão do ensinar a informação. Contudo, as discussões aprofundadas sobre das abordagens fundamentais desse movimento não acompanharam tal desenvolvimento: o relatório de 1974 é pouco conhecido e estudado e suas premissas históricas e sociais pouco refletidas. Em geral, e também no Brasil, o texto de Zurkowski é ligeiramente citado dentro de um cenário de histórico do movimento e para endossar iniciativas, sem uma reflexão que busque considerar os atuais quadros socioculturais do país, ação necessária para a resolução de complexos aspectos da sociedade, que envolvem a vinculação entre Informação e Educação.

Visualizamos assim, no Brasil e no exterior, a adesão pouco refletida de diferentes instituições e profissionais a um "discurso de autoridade" promovido por organismos como a ALA (American Library Association), a IFLA (International Federation Library Association) e UNESCO (United Nations Educational, Scientific and Cultural Organization), que assumem a Information Literacy como "farol da sociedade da informação" (IFLA, 2005, p.01) e que acabam por impulsionar o discurso deste movimento sem questionamento ou reflexão.

Sendo a Information Literacy um movimento de proporções globais, o estudo discursivo do relatório de Zurkowski mostra-se importante para a compreensão de suas ideias centrais, bem como sua ótica de aprendizagem informacional, suas concepções de informação e de educação, assim como o entendimento de seu contexto e significado histórico, cultural e educacional. 
Seminário de Pesquisa em Ciência da Informação do PPGCI 2017

Escola de Comunicações e Artes - Universidade de São Paulo

\section{Desenvolvimento}

\section{$2.1 \quad$ Método}

Para o desenvolvimento da presente pesquisa estamos utilizando o método de Análise do Discurso, de acordo com as orientações de Freire (2014), que afirma que essa opção pode "explicitar o processo de constituição de sentido a partir da língua" (FREIRE, 2014, p.10). Para Gregolin (1995), este método leva à compreensão da construção de discursos por meio do entendimento de suas questões internas e externas. Para Freire (2014, p.18), a produção da análise do discurso "envolve circunscrição do conceito-análise e a escolha e interpretação e análise do corpus, por meio de perguntas heurísticas”. Desse modo, apresentamos tais questões: "1 Qual o conceito análise presente no texto? 2 Como o texto constrói o conceitoanálise? 3 A que discurso pertence o conceito-análise da forma que o texto [o] constrói?” (FREIRE, 2014, p.21). Segundo o autor, o analista deve se abster de expor sua opinião, mas apenas colaborar para explicitar o discurso e como este foi construído.

\subsection{Resultados parciais}

O conceito-análise que buscamos no texto é: no discurso inicial de Zurkowski, o que é a Information Literacy (IL), seus fundamentos e a base dos argumentos de seu autor. No relatório de 1974, Zurkowski nos dá a definição de IL: "Pessoas treinadas na aplicação dos recursos de informação para o seu trabalho podem ser chamadas de information literates" (ZURKOWSKI, 1974, p.6, tradução nossa). Para isso, sua proposta é "capacitar todos os cidadãos no uso das ferramentas de informação" (ZURKOWSKI, 1974, p.27, tradução nossa).

Desta forma, podemos entender que no discurso inicial, a IL se traduz em treinamento, com o objetivo de tornar os americanos hábeis no uso das ferramentas tecnológicas de informação. Zurkowski afirma que as relações entre as bibliotecas e a Indústria da Informação estão em transição e, por isso, a necessidade de se adaptar às novas realidades: "Uma multiplicidade de vias de acesso e fontes surgiram [...] estes são mal compreendidos e vastamente subutilizados" (ZURKOWSKI, 1974, p.1, tradução nossa). No decorrer do relatório, ele nos traz questões econômicas e de valor da informação: “A informação tem valor em proporção direta com o controle que fornece", e segue: "O usuário está disposto a pagar pelos serviços que aumentam seu controle [...] muitos ainda sentem que a informação, como o ar, é um bem livre" (ZURKOWSKI, 1974, p.6).

Entendemos que o conceito-análise foi construído em um cenário no qual as relações das bibliotecas com as indústrias de informação e com os usuários estão em mudança. Novos recursos e serviços são disponibilizados, requerendo treinamento adequado para sua 
Seminário de Pesquisa em Ciência da Informação do PPGCI 2017

Escola de Comunicações e Artes - Universidade de São Paulo

utilização, o que evidencia a proposta da Information Literacy. Assim, tornar as pessoas aptas a operar os recursos oferecidos pela indústria da informação, das quais Zurkowski é portavoz, mostra-se essencial para a garantia de saúde financeira das indústrias de informação americanas.

O discurso que aborda as mudanças na sociedade e as relações com a informação, as tecnologias e a globalização é, pois, o da dita Sociedade da Informação, que "surgiu nos anos 70, num quadro preciso, o da teoria econômica da sociedade pós-industrial" (CORNU et al, 2005, p.10). Nesse modelo de sociedade, observa-se "uma dupla imposição: a das técnicas mediáticas [...] e a da economia imaterial em que o conhecimento é antes de tudo o fator de eficácia e performance. A razão instrumental está no coração desse processo [...]” (CORNU et al., 2005. p. 09).

Assim, o discurso da Information literacy, nos moldes propostos por Zurkowski, mostra-se alinhado aos termos definidos acima. O relatório está enraizando não só na sociedade da informação, como focado nas oportunidades econômicas. Economicista, nasce diretamente vinculado à economia da informação, afinado com perspectivas de lucros para as indústrias que Zurkowski representa.

\section{Considerações Finais}

Pelo exposto, nota-se que as afirmações são direcionadas: treinar para a utilização da tecnologia que é disponibilizada pelas indústrias da associação que Zurkowski representava. Mesmo que ainda de maneira parcial, a análise do documento por ele elaborado evidencia que os ideais iniciais do movimento da Information Literacy estão mais interessados em treinar para o uso dos recursos tecnológicos, preparar usuários para as tecnologias que educar para a informação, com o propósito de tornar os cidadãos protagonistas e críticos. Busca-se, muito mais, estimular operadores de tecnologias que desconhecem até então. Desse modo, esta concepção não responde às demandas que requerem pessoas críticas, capazes, sim, de operar recursos, mas muito mais que isso, em condições de questionar as informações, que não são simplesmente assimiladas, mas apropriadas por meio de profunda compreensão, tal como propõe a Infoeducação (PERROTTI, E.; PIERUCCINI, I., 2008; 2016) abordagem das relações entre Informação e Educação em desenvolvimento na ECA/USP, desde o ano 2000. Por meio do diálogo e da compreensão de aspectos cognitivos, sociais e culturais, a Infoeducação rompe com padrões pré-estabelecidos para ir além dos recursos tecnológicos, o instrumentalismo e o consumismo unidirecional da informação. A Infoeducação pretende proporcionar condições de os cidadãos se tornarem verdadeiros protagonistas informacionais, 
Seminário de Pesquisa em Ciência da Informação do PPGCI 2017

Escola de Comunicações e Artes - Universidade de São Paulo

isto é, sejam capazes de exercer a cidadania cultural num mundo superpovoado de informações que se renovam incessantemente, colocando as significações em processos de transformação que beiram à vertigem.

\section{Referências}

CORNU, B. et al. Vous avez dit « société de l'information »? In.: COMISSION

FRANÇAISE POUR L'UNESCO. La « société de l'information » :glossaire critique. [s.l.]: La Documentation française, 2005. p.09-35. Tradução Ivete Pieruccini. No prelo

FREIRE, S. Análise de discurso: procedimentos metodológicos. Manaus: Instituto Census, 2014.

GREGOLIN, M.R.V. A análise do discurso: conceitos e aplicações. Alfa, São Paulo, n.39, p.13-21, 1995. Disponível em: http://seer.fclar.unesp.br/alfa/article/viewFile/3967/3642.

INTERNATIONAL FEDERATION OF LIBRARY ASSOCIATIONS AND

INSTITUTIONS. Faróis da sociedade de informação: Declaração de Alexandria sobre competência informacional e aprendizado ao longo da vida. Alexandria: IFLA Publicações , 2005. Disponível em: https://www.ifla.org/files/assets/wsis/Documents/beaconinfsoc-pt.pdf

PERROTTI, E.; PIERUCCINI, I. Infoeducação: saberes e fazeres da contemporaneidade. In: LARA, M.L.G, FUJINO, A. NORONHA, D.P. (orgs.) Informação e contemporaneidade: perspectivas. Recife: Néctar, 2008. p.46-97.

PERROTTI, E.; PIERUCCINI, I. Infoéducaion: ceci n'est pas une pipe. À la recherche d'une troisième rive. Mediadoc Apden, Paris, n.16, p.18-23, juin. 2016.

ZURKOWSKI, P. G. The Information Service Environment Relationships and Priorities: report 5. Washington, D.C., National Commission on Libraries and Information Science, Nov 1974. Disponível em: http://files.eric.ed.gov/fulltext/ED100391.pdf

\section{Sobre os autores}

Leandro dos Santos Nascimento

Bibliotecário - Universidade Estadual de Campinas

Mestrando em Ciência da Informação - Universidade de São Paulo

le_santos20@yahoo.com.br

\section{Edmir Perrotti}

Professor Doutor

Universidade de São Paulo

perrotti@usp.br 